\title{
Sciendo
}

\section{Covid 19 between globalisation, mobility and complexity}

\author{
Alessandro Figus \\ International Institute of Management IMI-Nova, Moldova \\ e-mail: vicerector.int.iminova@gmail.com \\ Ludovico de Serio \\ Zhubanov Regional State University, Kazakhstan \\ email: ludovico.deserio@gmail.com
}

DOI: $10.2478 /$ gssfj-2020-0008

\begin{abstract}
In the article, the authors analyse how Covid 19 have influenced and modified the dynamics generated by the globalization processes in the last decades, in comparison with other recent global crises. Globalization is here treated as a complex phenomenon, that led to major changes in every aspect of modern society, on a large scale and on a small one. To this purpose, an in-depth analysis of the current socio-economic scenario in both developed and developing countries is carried out, with a focus on the data regarding the sectors that were most influenced by the pandemic outbreak.
\end{abstract}

Keywords: Covid 19, globalisation, internationalisation, mobility, complexity

\section{Introduction}

At the present time the health emergency caused by the Coronavirus is certainly not over, but we are confident that during 2020 the world has been upset by this event. We do not know what will happen next year, indeed what will happen in the coming months in our lives and in those of all the countries involved so far? In the meantime, we are registering the first effects of Covid 19 on our habits, we pay a lot of attention to medium- and long-term economic forecasts, especially thinking about the complexity of the new globalization (Morin E, Abouessalam S, 2020).

The coronavirus crisis did not only lead to the "Great Economic Pandemic". It marked the beginning of a new era, a new World Order, a new globalization.

It is a major contemporary historical event; it is truly "international" and a major world security issue. International solidarity with health personnel around the world should serve as an incentive for the world to know how to respond in an extraordinary way and reverse the circumstances.

From the perspective of the global response to the Coronavirus, we have seen a lack of international coordination. To observers who do not have much knowledge of "global policy" it may appear as a new and surprising form, it is part of a transnational 
strategy of major international issues, a bit like migration, environmental issues, the issue of terrorism, global finance, etc. etc..

Therefore, there is a need to change course and encourage global cooperation on a large scale, since globalization cannot be just social networks and online sales, digitalization without governance, etc. etc.

Coronavirus places the spotlight on the problem of international relations, exposing global possibilities. The global spread of a disease becomes an opportunity to reflect internationally on how to coordinate globalization through new forms of unprecedented forms of international cooperation, highlights the failure of some organizations that today are mummified inside glass palaces (think for example the UN, FAO, WHO, and why not the European Union).

The pandemic crosses state borders, but state powers and local governments become protagonists in the absence of international strategy, and when globalization fails along with communication, we hope that liberal systems do not fail to the detriment of authoritarian ones, even if there seems to be more deaths in the US than in Xi's China.

After all, international integration has favored the speed with which this pandemic has spread, which is not surprising in the complex and globalized era of mass tourism, with thousands of flights connecting the most disparate parts of the world and cities twice its size, these were and are in fact centers of international transportation.

Global supply chains have been severely disrupted, almost every sector has gone into crisis. Governments emerging from this crisis will think twice about the benefits of global integration and interdependence. Barriers to travel are also likely to remain, as security measures did in the aftermath of the $9 / 11$ terrorist attacks.

As we have already mentioned, there is the problem of authoritarian governments that could prove to be more solid in the face of the crisis, more organized. China, for example, could be the target of new restrictions, as it was the source of the infection, but it is precisely China that has shown the need for multilateral cooperation with its willingness to provide medical assistance and supplies to many countries, that a complex but organized system with enviable governance, the first country to suffer from the coronavirus, and the first to come out of it, and given the size of its community and scientific structures, has been central to international collaboration not only in medical research.

The fact is that in the post-Covid-19 world, there are risks associated with globalization and the complexity of its balances. In this sense, international trade is likely to take new forms, because it may well happen that trade in physical goods and mobility of people will decline whereas digital globalization may develop further, gaining considerable importance.

Indeed, widespread lockdown has shown companies and governments how much "the net, the internet" can achieve in terms of effective remote working and online services. One such example is video conferencing versus face-to-face meetings, which can be more efficient and time-saving; and distance learning can actually facilitate quality education for many more students, will likely be a reality in the future and will probably change thinking and reduce operating costs. 
Although companies may seek to reduce vulnerabilities and some may be inclined to bring home international production, the principle of comparative advantage will continue to exist as it will always be more economically efficient to obtain some goods and materials from other countries. Thus, it is conceivable that physical goods flows will be replaced by digital services (Figus, 2020).

Companies looking to diversify their supplier networks, even with some redundancy, even if it increases the cost of their production, might try and compensate with more automation. Supply chains are also likely to become less global and more regional. This is what has happened in Asia over the past three decades, where intra-Asian trade, has increased dramatically and this has led to large shifts in personnel. The system comes into crisis with the onset of the pandemic. It wasn't enough to have Brexit, now Covid 19 has thrown in as well.

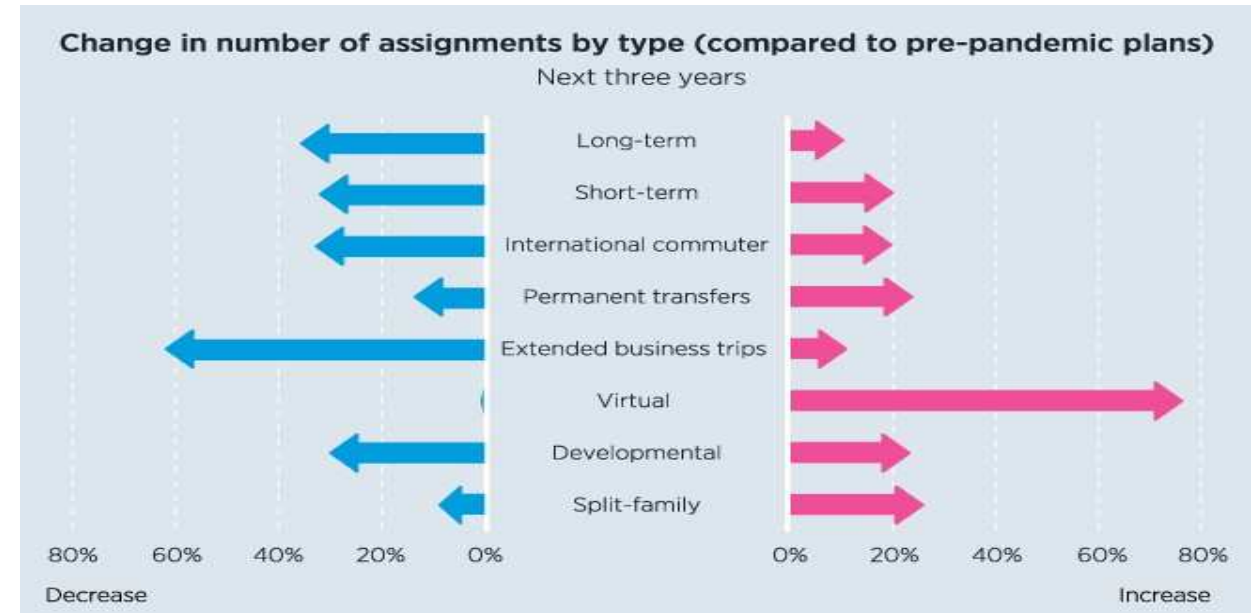

Figure 1 - Change in number of assignments by type (compared to pre-pandemic plans) (Source: "Global Mobility and Covid-19”, ECA International, 2020).

From the table we can better understand the situation, which is due first to the phenomenon of globalization and then to the crisis due to the pandemic event. We are not reporting it by chance, but as a representative example of the crisis. Due to the repatriations and the impossibility of activating new assignments, in fact, many companies have seen a transformation of the system and a decrease in the number of expatriates.

Most multinationals are only now resuming planning new international assignments for when they travel abroad, but this is programming, pure programming. In reality, nothing is certain and it is not known when the economic system will start marching again, and when these mobilities will become possible again. The world system has entered a crisis and the immigration aspects are the challenge faced by global mobility teams.

Looking to the future, the return to normal for international travel is still a long way off, it is very likely that assignments with shorter durations and less complex to initiate have been postponed indefinitely, not to mention travel, even tourist travel. 
There is a general expectation that the number of travelers and that sooner or later there will be a concrete return to pre-Covid19 normality. The world of tourism is changing, the internationalization of workers is changing, the educational system is changing as well, let's think for example of what the Erasmus program has meant. Tourism, then a source of wealth, was worth a little less than 150 billion euros in Italy, a figure equal to $12 \%$ of GDP, generated by a supply chain of over 200 thousand accommodation businesses and 12 thousand travel agencies. Yet today the Covid-19 epidemic has spared no one, especially those who travel, representing a significant threat to the entire travel industry, both for those who work in it and for those who want to continue to travel.

The thumb in the wound: travel! These had become the symbol of globalization, but years of development were erased in a few months of pandemic.

The system went into crisis, the symbol of globalization, the symbol of economic prosperity and international strategy where both mobility for work and mobility for pleasure had become a complex system in which to operate on a daily basis.

The point is that international trade relations always come with risks. But the prerogatives of globally interconnected economies far outweigh the costs.

With globalization, especially in recent decades, hundreds of millions of people have been lifted out of poverty around the world by increased global trade, driven by the fall of trade barriers and tariffs and a system of anti-globalization (Stiglitz J.E, 2018). We must not allow this pandemic to erase what has been achieved.

\section{Globalization, complexity and pandemic}

Restrictions on internal and international movements of people, which were multiplying and spreading from one continent to another, before the 2020 pandemic, as we mentioned in the introduction, could not have affected a widespread and shared globalization, a heated strategy of internationalization.

No one could have predicted that tourism, migration, international movements of college students, or sports as forms of global projection could have been slowed down. Globalization was based on displacement, not only physical but also ideological, and simultaneously on the use of retailing and the power of communication. The dimension of globalization, more dynamic in postglobalization, would not have found obstacles if not in an external factor, and so promptly was the case. The great recession and post-economy could be suddenly interrupted (Osterhammel J., Petersson N.P, 2005).

While trade in digital services or goods, productive investments abroad or technological innovations might continue to develop, reinventing themselves to some extent, the question of restrictions on international movements of people remains.

The World Health Organization was as incapable of predicting this pandemic as economists were in the face of the 2008 crisis, which then included institutions such as the World Bank or the International Monetary Fund (https://unric.org, 2020). 
The graph shows the "global GDP Growth" over the period 1995-2020, highlights the global crisis of 2008 and the current crisis of 2020, the only difference that the latter is right outside the economy and is due to the Covid-19 pandemic.

Meanwhile the Covid-19 pandemic is still ongoing and appears to be of lesser magnitude. The 2008-2009 crisis is not reflected in the Index until 2011 and therefore, most likely, the effects of the Covid-19 pandemic crisis will not affect the Index values until 2021 or 2022 or beyond; much depends on when the crisis ends.

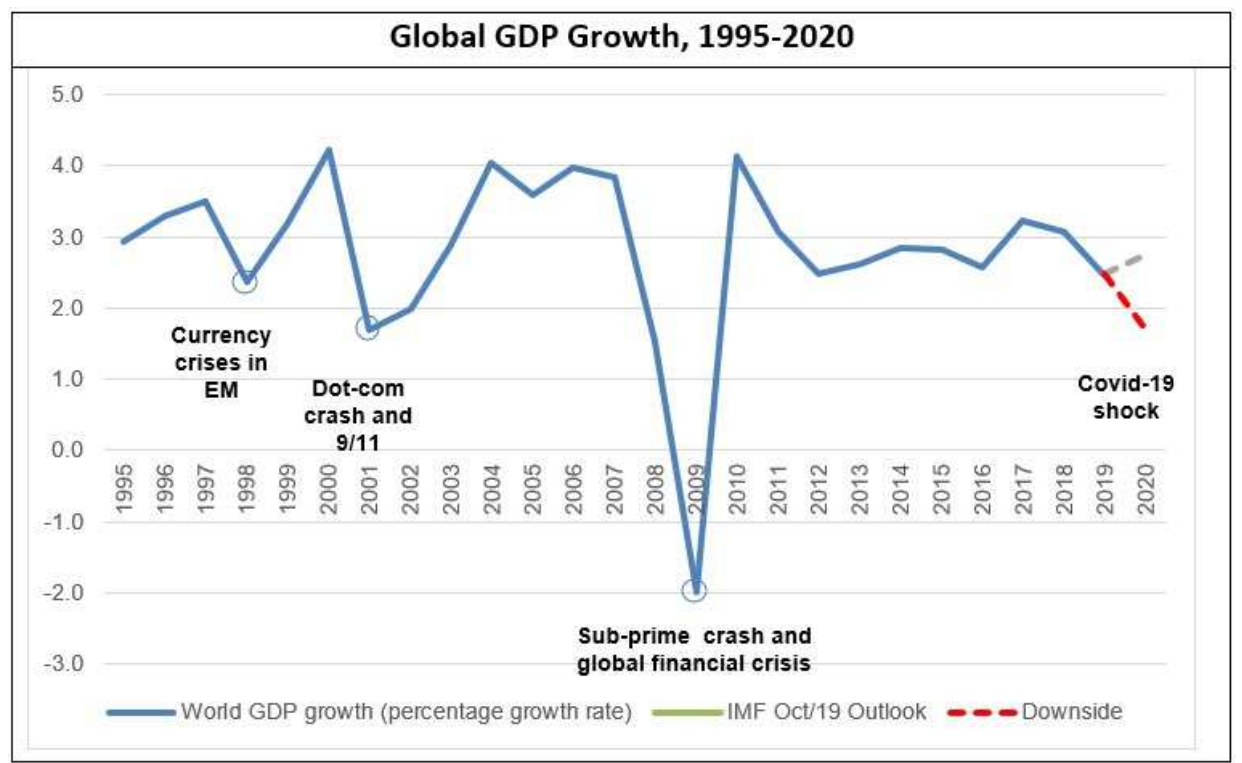

Figure 2 - Global GDP Growth, 1995-2020 - source UNCTAD.org

In Figure 2 we graphically compare the 2008-2009 economic crisis and well understand how this is far deeper than the economic crisis due to the Covid 19 pandemic.

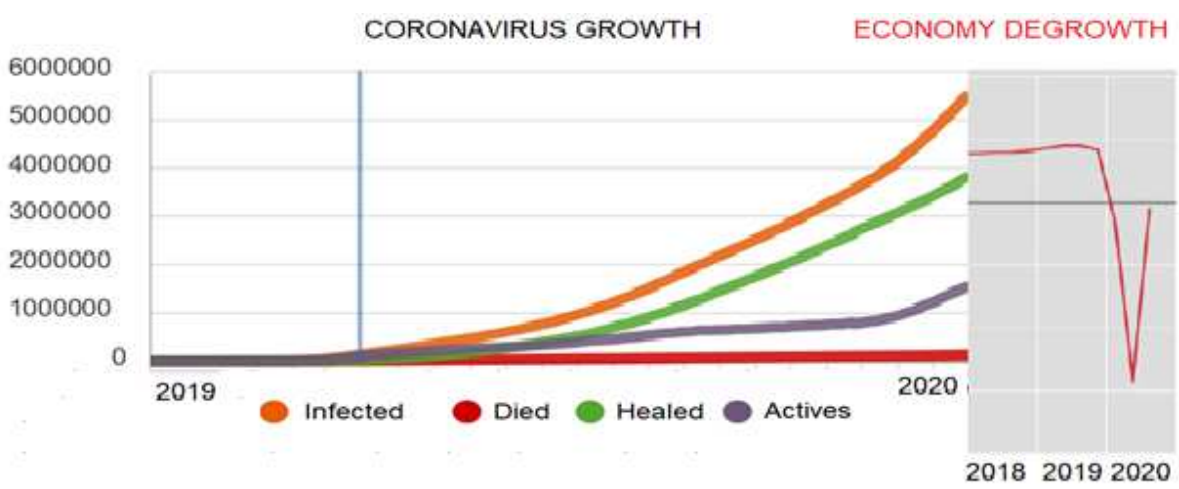

Figure 3 - World coronavirus Covid 19 OMS data (elaborated by the authors) 
In sum, in general terms and except for the last year for which we have data, the world has not undergone a process of deglobalization (Osterhammel, Petersson, 2005). However, there is a slowdown or stagnation that could lead to effective deglobalization if the trend of the last year is maintained or accentuated.

From the point of view of the effect on globalization, we could also observe syndetic behavior, which is explained by the correlation between different aspects of international relations. In fact, if we take into account the technological developments in soft globalization these have their effect on the behavior of world production and exchange of complex artifacts and this appears as the economic dimension, where tourism, culture or education go closely linked to the exchange of services (which in fact is the real economic globalization). Therefore, it is interesting to compare what the balance of trade was before and after Covid.

If we analyze, for example, the Italian case, for which we have up-to-date data, we can better understand that in April 2020, therefore in full pandemic peak and lockdown, Italian foreign trade has recorded an unprecedented contraction due to the Covid crisis. According to ISTAT data (Italian Institute for statistic) we see that the Italian trade balance recorded in April 2020 a deficit of 1.157 billion Euros from the surplus of 2.851 billion marked in April 2019.

In the month under observation the export itself recorded a year-on-year decline of $41.6 \%$, the import of $33.7 \%$. The trade balance with EU countries in April recorded a deficit of 1.004 billion euros from the deficit of 77 million in the same month of 2019. Exports decreased by 39.4\% year-on-year, imports by 34.6\%. The effects of Covid-19 on trade, we can say that the Italian system has come to a standstill, but everyone hopes that exports will be the driving force of recovery in the coming years According to ICE-Prometeia estimates, in 2020 Italian exports will suffer a sharp drop, equal to $-12 \%$ compared to 2019 , only to start again in the following two years, with growth rates of $+7.4 \%$ in 2021 and $+5.2 \%$ in 2022 . It will take two years for Italy to return to 2019 export levels (see Figure 4 prepared on the basis of these data). 


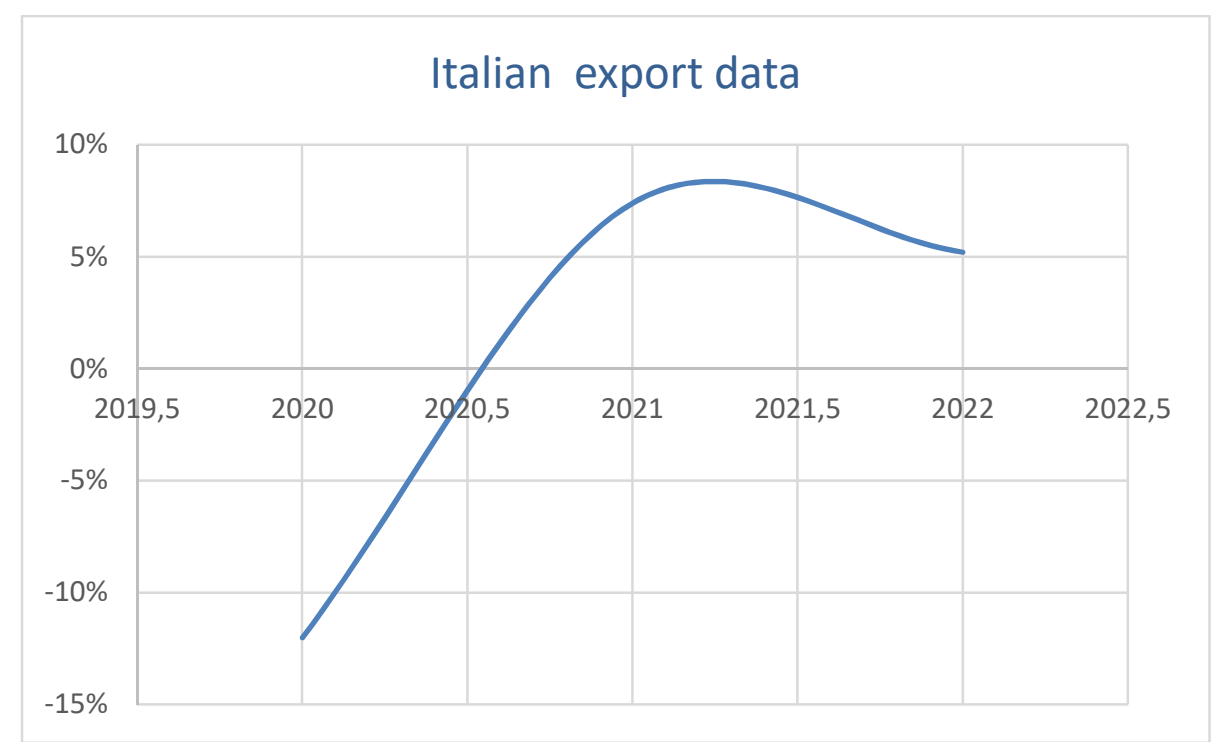

Figure 4 -Source ICE-Prometia prevision (elaborated by the authors)

In short, in April, the fall in foreign demand and the measures taken to contain the Covid-19 epidemic in Italy and the main partner countries led to a contraction, both conjunctural and tendential, in foreign trade. The pandemic for one of the countries in the world most affected by Covid-19 highlights the crisis in a significant way, a worrying economic situation.

That the economy has come to a standstill due to the Covid-19 effect is evidenced by the worldwide and European reduction of both imports and exports, a lockdown of movements that we can define as "globalized. We can see this in Figure 5 (source Eurostat, 2020).

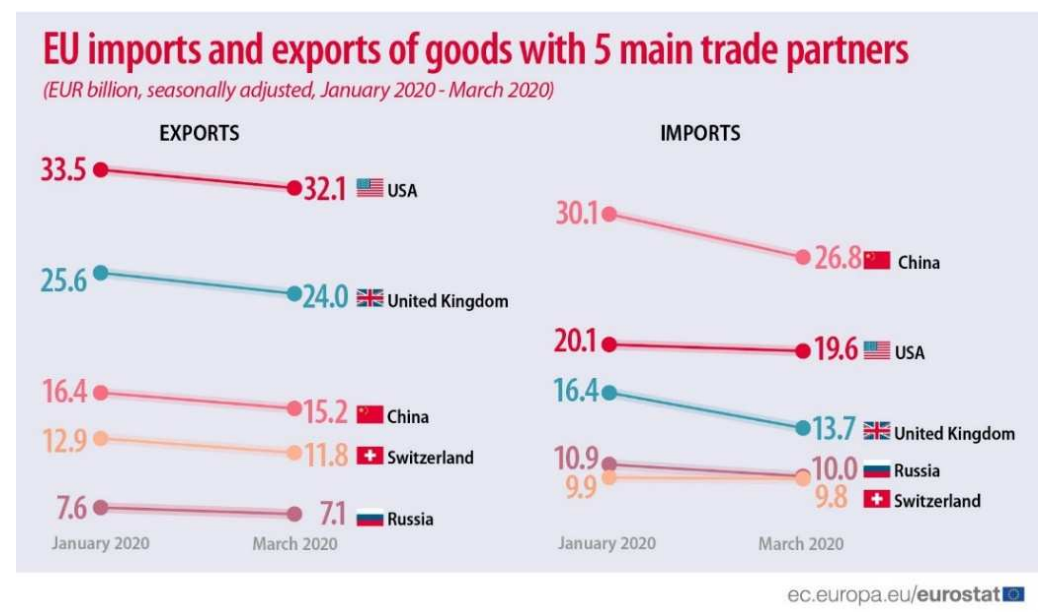

Figure 5 - EU imports and exports of goods with 5 main trade partners (source Eurostat, 2020) 
Having said that the best example to demonstrate the connection between the countries of the world is the pandemic produced because of the virus called COVID19 , because in a very short time the virus has circulated throughout the planet generating negative effects on public health, economy and society in general. In fact, this international relationship can be understood as a consequence of globalization, which is produced by the existing interdependence between economic, political, social and cultural factors of the countries of the world seen in its complexity. It is true that globalization can be understood from a capitalist perspective, i.e. where there is a pre-eminence of capital, but we prefer to understand globalization as a way to increase wealth and opportunities for everybody. In the end it becomes a complex but democratic process within the reach of all and everyone.

Throughout the world today, concerns persist about the advantages and disadvantages of globalization where the benefits produced by the trans nationalization of the processes of production, distribution and consumption of goods and services do not generate the same profits for those involved in this process. The pandemic has highlighted the issue of globalization, its impact on world society, especially and the crisis due to Covid-19 has highlighted the effects of the phenomenon, its economic and socio-political impact, the advantages and disadvantages that arise from it. The slowdown of post-pandemic globalization will lead us to reflect at $360^{\circ}$ allowing to broaden the debate on the advantages or damages of globalization is a process that configures the interaction of a significant number of factors that transcend the purely economic one, therefore, must also be understood as a systemic phenomenon involving social and political factors, without which it would be impossible to even come close to interpreting the system (Osterhammel J., Petersson N.P, 2005). Certainly, globalization is a complex system and should be understood as a process of inclusion that is based on international interaction, namely, it has a planetary character, which means that the phenomena that occur in one place on the planet, are projected in the rest of the world.

Globalization has a universal character and encompasses all human spheres, positioning itself for its asymmetrical condition, therefore a different meaning depending on its placement for what is happening and where it is happening and should be treated as a redefinition of social relations. This is due to the development of information and communication technologies that give society the opportunity to exchange its culture based on human relations and interact at the global level. It is necessary to consider globalization as a social aspect in which phenomena such as migration, employment, income distribution, poverty, etc. etc. are highlighted. It is evident how correlated any crisis is today, precisely because social relations are being reconfigured and the State's role and political function are being redefined. Everything is globalized, everything is connected, everything is tremendously complex.

If we look once again at the economic question in relation to globalization, we see that the commercial and cultural interactions that globalization implies lead to economic development. This phenomenon has tended to deepen the complexities of the economic cycle and the reactions to it such as any crises that may arise, especially 
in countries considered to be in the process of development. Think, for example, of the difficult situation experienced by the African continent and how Covid 19 or other pandemics have highlighted its critical aspects. One of the main characteristics of these is the high concentration of raw materials and, to a lesser extent, specialized production. In developed countries, the aspect of the globalization system shows large concentrations of capital in a few people or companies, and this impact has effects in countries with unstable political and economic conditions, in this case globalization should be seen as a phase in the history of capital whose lineage has joined the society in different ways in the same system and this can be seen, as a dialectic of continuity and discontinuity. Once again, we are faced with a complex model of society, poorly governed at the international level and with a propensity for mobility. In this sense, globalization is a set of ideas centered on the increasing integration of the market, which, in its dominant form, neoliberalism, materializes in a policy framework of deregulation, liberalization and privatization unconditional, think of the big companies that today in pandemic period take advantage of the crisis. A significant example is the "globalized" company Amazon. As we see in figure 6 the market capitalization that Amazon has gained especially in 2020.

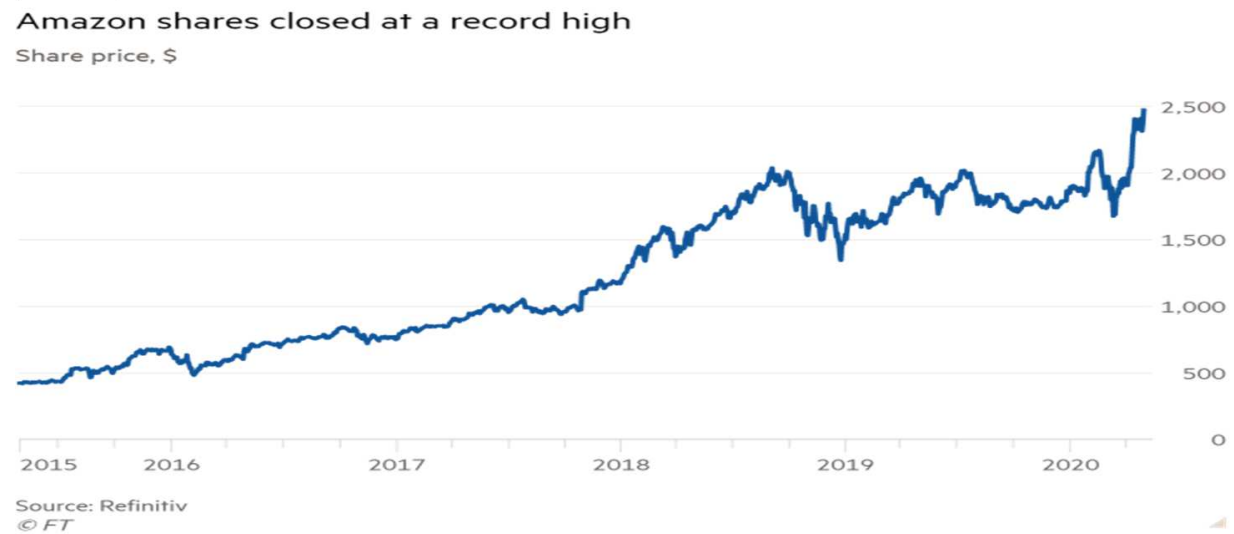

Table 5- source Refinitiv-FT 2020

Covid 19 has been a financial boon for these online companies. At the beginning of the year, the e-commerce giant was worth about $\$ 920$ billion. After the stock rebounded from its decline in March and hit new record highs, the company is now worth $\$ 1.490$ billion. That now makes Amazon one of the largest companies in the world, trailing only Microsoft, with a value of $\$ 1.540$ billion, and Apple, with a value of $\$ 1.61$ trillion. Amazon's stock has risen more than 60 percent this year and is now trading at about $\$ 3,000$. The stock bottomed out at about $\$ 1,600$ in mid-March when the stock market crashed following widespread shutdowns due to the coronavirus pandemic. Since then, shares have rebounded, closing above $\$ 3,000$ per stock for the first time on July 6.

These characteristics of the global market have polarized trade relations, but at the same time set barriers and socio-economic conditions to implement a dominant and 
unequal system, which due to the rich supply of technological services constituted the real economic result of the process: inequality and dependence on the conditions of well-being and prosperity so coveted, along with public policies that aimed at deregulation or liberalization of national markets. If we look back to World War II, we see that the terms of trade were strengthened with the new industrialization, which led to the positioning of transnational corporations and companies that had already experienced significant commercial expansion from the 1950s onwards. All of this led to determine the essence of the new conditions of economic globalization: the innovation of the tools of the digital economy and their relationship in global information management. In practice, economic globalization represents the end of the state as the main regulator of economic activity. Added to this is the process of development of the welfare system, especially in European countries, which, however, has ceased to guarantee economic growth and full employment. In developing countries, on the other hand, the model of state intervention, based on protectionist policies, which has manifested itself as a foreign debt crisis, has been exhausted.

The public debt has become the critical point of the globalized economy and the differentiation between states and states; this happens even within the European Union, let's imagine how it is governed in other realities.

Therefore, we can say that until yesterday, the term globalization reached a rapid diffusion under the impulse of electronic media and of the different neoliberal governments, in the political, economic, social and cultural field. However, we cannot forget that this term hides a complex process that has caused the causes that unfortunately are often confused with the consequences. The generalization of a model of social organization does not allow us to fully understand what globalization really is.

In order to explain better, we would like to use an example, which, among other things, will fit like a glove when we conclude by addressing the topic of Covid 19, globalization and the post-pandemic period. Let's talk about China, a country with more than a billion inhabitants, the most populous country in the world and where labor is one of the cheapest in the world.

Today, all countries turn to China to obtain advantages in terms of absolute costs of its workforce, both in developed and developing countries flock to China exploiting cheap labor.

This obviously generates positive effects for China, but at the same time negative effects on the price of labor in other countries, which receive products at low prices because of the cheap labor that makes up the cost structure of the product imported from that country, also affecting employment, a key factor in the economic circuit. This explains what globalization is, a phenomenon that in the last two decades has revolved around forms of communication and global marketing that distinguishes developed and underdeveloped countries, evidently under the protection of technological development in information systems, the establishment of a new world order and a reconfiguration of the variables that guaranteed the hierarchy of domain, power or influence that have also been modified. 
Now we are in a new crisis but perhaps globalization has nothing to do with it.

\section{Conclusion}

In conclusion, the only thing we fail to see is how the post-Covid 19 process of globalization can be modified. The social face of globalization has to do directly with the impact of this process on the well-being, life and work of individuals, families and societies. There are countless perceptions regarding this, we are convinced that in a short time we will experience a return to normality.

However, concern is often expressed about the effects on employment and working conditions, population income and social protection. In addition, concerns are raised about the loss of sovereignty of countries as a result of the internationalization of policies and globalization, the culture that leads to integration or marginalization of societies. The pandemic crisis has highlighted the problems but has also taken out of the way all those artificial actions that already marked the 2008-2009 economic crisis. Unfortunately, all this has led to progressive inequality, a consequence of the evolution of remuneration between sectors, productivity strata and skill levels; as well as exclusion, due to the lack of quality jobs, poor coverage of social protection systems and increasing job insecurity.

These are effects of globalization in times of crisis that do not generate policies that work in every regional reality. The world system is divided into a pyramidal structure led by global economic powers, which have defined, under their own interest, the organization of economic and social structures and the world order. In addition to all this, there are globalized companies holding immense capital that act in a globalized market, and that control the markets, often influencing them more than the rulers can.

Inevitably, the pandemic caused by the Covid 19 coronavirus will generate impacts on different scales in almost every country in the world; a situation that was unexpected, but that has brought substantial changes in political, social, production, consumption, and even personal relationships around the world (Treccani, 2020). Indeed, no one was ready to reverse such a crisis, but the truth is that it generated sudden changes in people's lives thanks to compulsory imprisonment.

Consumption and social life have changed, and this will undoubtedly have consequences on people's views of the importance of things and their relationship with the world. There is a need to understand the role of a new evolution of the complex globalized system, where the coronavirus crisis has highlighted the structural weaknesses of the world system that has put the governments of all countries under control. It has become clear that, in the interest of economic development, social protection systems are being sacrificed.

All countries have tried to react to the crisis, and in the smaller economies inequality, poverty, precariousness of work, health systems, etc., have continued to rise. All these phenomena cannot be attributed to globalization and giving priority to economic factors exacerbates their negative effects on social protection systems. Globalization, 
after all, has intensified a political and economic model that has focused more on the returns to capital and the imposition of technocratic and practical political ideologies, particularly in favor of economic powers, its transnationals and its political castes. This shows the uneven system of governance that exists globally, to the detriment of countries with weak economies and deep social problems, which is likely, with the potential slowdown of globalization, to be significantly more affected.

What we would like to see in the future perspective is a new complex but transparent system of globalization, where international governance manages crises for the benefit of all. A new global coordination. Today glass palaces, the UN, the WHO, even in part the European Union must open up to shared international strategic cooperation, no one is more able to promote or obtain a coordinated response to threats. Global crises must be faced with global instruments, and although a homogenization and a coordinated world system are sought, this unfortunately works only for the accumulation of capital in the powers of the world.

\section{References}

Treccani, Dizionario Medicina, 2020.

Figus A., Coronavirus COVID - 19, a complex issue between health, economy, politics, and communication, De Gruyter open access, GSSFJ 1, 1-14, 2020.

Morin E, Abouessalam S, Cambiamo strada. Le 15 lezioni del coronavirus, Cortina Raffaello, 2020.

Osterhammel J., Petersson N.P., Storia della globalizzazione. Dimensioni, processi, epoche, Il Mulino, 2005.

Stiglitz J.E., La globalizzazione e i suoi oppositori. Antiglobalizzazione nell'era di Trump. Einaudi, 2018.

\section{Web references}

https://ec.europa.eu/eurostat/data/database

https://www.istat.it/en/external-trade

https://www.refinitiv.com/en

https://eca-international.com/insights/blog/december-2020/the-impact-of-covid-19-

on-global-mobility

https://unctad.org/press-material/economic-impact-covid-19-can-policy-makers-

avert-multi-trillion-dollar-crisis 